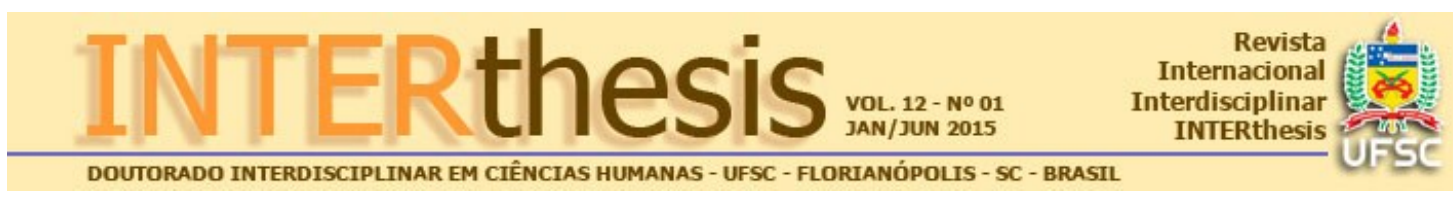

\title{
DEMOCRACIA REPRESENTATIVA: AS CRÍTICAS DE CARL SCHMITT
}

Alexandre Franco de Sá1

\section{Resumo:}

O presente trabalho procura, por um lado, mostrar a base do conceito schmittiano de representação. Ele mostra de que modo este conceito se liga essencialmente aos conceitos de mediação e de decisão. A partir daí, o artigo mostra, por outro lado, como o conceito de representação lhe permite desenvolver um pensamento político que consegue compreender criticamente os problemas fundamentais das sociedades democráticas contemporâneas.

Palavras-chave: Representação. Mediação. Decisão. Democracia.

O tema que me foi sugerido para a presente lição inaugural - as críticas de Carl Schmitt à democracia representativa - tem inevitavelmente como pano de fundo a interrogação em torno do modo como se confrontou com a "democracia", a "legitimidade política" ou o "Estado de direito" o pensamento de um autor de cariz marcadamente autoritário, cujo envolvimento com o nazismo the valeu independentemente da sua justiça ou injustiça- o título de Kronjurist do Terceiro Reich. A sugestão de um tal pano de fundo pressupõe, portanto, uma perspectiva que parte do princípio de que se vai observar, com distanciamento, os contornos de um pensador consideradoum "inimigo perigoso": um inimigo que revelaria uma mentalidade tirânica que, enquanto tal, não poderia deixar de ser recriminada ${ }^{2} . \mathrm{Na}$ minha aproximação ao autor, gostaria, antes de mais, de dar um passo atrás em relação a uma abordagem deste tipo. De uma forma geral, a abordagem de um pensador político como um "inimigo perigoso" - como um representante do mal, da injustiça, da violência ou da iniquidade - tende a transformar-se num "ataque" que frequentemente distorce e bloqueia o acesso a uma compreensão do seu pensamento. No caso de Schmitt é possível encontrar numerosos exemplos de tais

1 Doutor em Filosofia pela Universidade de Coimbra, Portugal. Professor no Departamento de Filosofia, Comunicação e Informação da Faculdade de Letras da Universidade de Coimbra. Director do Curso de Licenciatura em Filosofia na Universidade de Coimbra, Coimbra, Portugal. E-Mail: alexandre sa@sapo.pt

2 Cf., porexemplo, GopalBalakrishnan. The Enemy: an Intellectual Portrait of Carl Schmitt. London, New York: Verso, 2000.

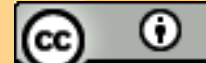


distorções. Para as evitar, umaabordagem do seu pensamento requer uma tentativa de pensá-lo numa atitude em que a sua compreensão, nas suas articulações internas e no seu contexto, se sobreponha à tendência para imediatamente o defender ou condenar.

Ao longo do seu percurso como pensador político, Schmitt não foi certamente um democrata nem um defensor da "democracia representativa". Contudo, uma tal afirmação de modo nenhum implica que Schmitt tenha de ser pensado como um defensor de uma tirania autocrática, do mesmo modo que não esclarece o modo como este pensou a democracia ou adoptou algumas posições intelectuais e políticas específicas no contexto da República de Weimar. E o mesmo se pode dizer em relação à sua subsequente adesão ao nacional-socialismo. É sabido que, depois de se ter manifestado explicitamente contra o Partido Nazi em 1932, Schmitt se apressa a aderir ao nazismo depois da chegada de Hitler ao poder, em Janeiro de 1933. No entanto, a evocação deste dado biográfico, por si só, diz muito pouco sobre o que Schmitt esperaria do triunfo político do nazismo,ou sobre o significado que atribuía à sua adesão.Que um pensador político como Schmitt (ou um filósofo como Martin Heidegger, por exemplo) tenha escolhido aderir ao Partido Nazi no contexto político alemão de 1933, é significativo para a compreensão do seu pensamento. Contudo, esta compreensão deve partir dele próprio, dirigindo-se depois para a consideração das escolhas e posições concretas a que ele conduziu, e não partir destas como fundamento para o emprego de rótulos que tornam dispensável justamente a necessidade de se confrontar com o próprio pensamento.

Tentando abordar o tema das críticas de Carl Schmitt à "democracia representativa", comecemos por considerar, antes de mais e num plano estritamente conceptual, o conceito de representação. Este conceito é, para Schmitt, um conceito central do pensamento político. Ele designa o modo como, de uma maneira geral, é geradaa unidade política. Schmitt aborda desde muito cedo o problema político da criação desta unidade, e a abordagem deste problema condu-lo, na qualidade de pensador católico, ao estabelecimento de um paralelo entre o Estado e a Igreja enquanto instituições que a propiciam. A partir deste paralelo, Schmitt enfatiza que a unidade política não pode deixar surgir sempre como a unificação de algo que, sendo intrinsecamente plural, conserva na sua unidade toda a sua pluralidade intrínseca. Ao contrário do que se passaria no decurso de um processo dialéctico, no 
qual o conflito entre opostos produziria, a partir da imanência do seu conflito, um terceiro termo mais elevado, uma "síntese" que superaria dialecticamente a diferença entre posição e contraposição, a unidade política produz unidade mantendo a contraposição entre os opostos na plenitude da sua tensão. Deste modo, longe de poder ser gerada a partir de uma dialéctica, ou de uma resolução imanente dos conflitos, a unidade política não pode deixar de ser criada, produzida por uma instância que, transcendendo os conflitos e sobrepondo-se-lhes, impõe-lhes uma unidade sem propriamente os dirimir. Poder-se-ia dizer que, se a unidade dialéctica seria gerada de baixo para cima, num processo em que a "síntese" conserva e nega simultaneamente as posições em conflito, num movimento em que tais posições são superadas ao serem arrebatadas para um patamar que as concilia e nega na sua unilateralidade, num movimento a que Hegel chamou "suprassunção" (Aufhebung), a unidade política criar-se-ia de cima para baixo, na medida em que a unidade desceria sobre os polos do conflito, impondo-se-lhes e instituindo a sua unidade sem os aproximar.

Vejamos como esta instituição da unidade política funcionariano contexto da Igreja católica. Depois de publicar na Revista católica Summa um artigo intitulado $A$ Visibilidade da Igreja, em 1917, é sobretudo no seu pequeno livro de 1923, Catolicismo Romano e Forma Política, considerado por Hans Barion um elogium da Igreja romana, que Schmitt aborda uma tal instituição. Neste livro, Schmitt recorre a uma expressão do teólogo protestante AdolfHanarck para caracterizar a Igreja católica: esta seria uma complexiooppositorum. No seio da Igreja, a multiplicidade, as diferenças e as tensões por elas geradas, seriam essencialmente ilimitadas. Politicamente, no seio da Igreja, há católicos de esquerda e de direita, legitimistas e revolucionários, autoritários e democratas, conservadores, liberais e socialistas. Sociologicamente, os católicos estendem-se desde o franciscano, na sua pobreza, simplicidade e amor pela natureza, até ao jesuíta, na sua subtileza, fineza intelectual e obstinação missionária, desde o monge mendicante ao abade da corte ou, dir-seia hoje, desde o teólogo da libertação ao sacerdote do Opus Dei. Mesmo dogmaticamente, como afirma Schmitt, a Igreja aparece marcada por este "complexo de opostos": "O Antigo e o Novo Testamento vigoram um ao lado do outro, o ou-um-ou-outro de Marcião é também aqui respondido com um tanto-umcomo-outro. Ao monoteísmo judaico e à sua transcendência absoluta são 
acrescentados, na doutrina da Trindade, tantos elementos de uma imanência de Deus que também aqui são pensáveis algumas mediações; e, por causa da sua veneração pelos santos, os ateus franceses e os metafísicos alemães, que redescobriram o politeísmo no século XIX, louvaram a Igreja, pois julgavam descobrir nela um paganismo saudável"3.

Diante desta multiplicidade ilimitada, a unidade política, no seio do catolicismo, não seria obtida através de uma superação da tensão entre posições antagónicas, resolvendo o seu conflito numa posição que as conciliasse e elevasse a uma "síntese" superior. Uma tal superação implicaria aquilo a que se poderia chamar uma limitação principial do antagonismo, isto é, implicaria que as posições em conflito fossem abandonadas na sua unilateralidade originária e, nesse sentido, descaracterizadas no seio da Igreja. Tal é justamente o que a complexiooppositorum não permite. Assim, longe de as conciliar, a Igreja institui a unidade entre as várias posições não na medida em que as concilia, mas na medida em que thes sobrepõe uma autoridade vinda de cima, representante da transcendência de Deus. No conflito efectivoentre posições antagónicas, a autoridade incontestada do Papa afirma-se como a depositária da possibilidade de uma decisão inapelável pela qual este possa ser resolvido e a unidade da Igreja assegurada. O dogma católico da infalibilidade papal, estabelecido em 1871 no Concílio Vaticano I, confirmaria precisamente a possibilidade de uma tal decisão.Na medida em que é o vigário de Cristo e, portanto, o seu "representante" sobre a Terra, o Papa teria, assim, como sua característica essencial, a infalibilidade e, nessa medida, a prerrogativa de decidir sem apelo, com autoridade absoluta, aquilo que entender necessário para o estabelecimento da unidade da Igreja. Na medida em o Papa é infalível, Roma pode falar em último lugar e encerrar um caso em que várias posições estejamem disputa no espaço da unidade da Igreja: Roma locuta, causa finita. E na medida em que a autoridade infalível do Papa pode dirimir um conflito desta maneira, a unidade da Igreja está assegurada e estabelecida acima dos conflitos, por maior que seja a tensão entre eles.

Se quisermos analisar, sob o paradigma da Igreja católica, o modo como Schmitt pensa a instituição da unidade política, poderíamos dizer que este assenta

${ }^{3}$ Carl Schmitt. Catolicismo Romano e Forma Politica. trad. Alexandre Franco de Sá. Lisboa: Hugin, 1998, p. 23.

R. Inter. Interdisc. INTERthesis, Florianópolis, v.12, n.1, p.130-146, Jan-Jun. 2015 
numa estrutura triádica em que se articulam três princípios distintos mas convergentes. Ao primeiro princípio a que nos referimos poderíamos chamar precisamenteprincípio darepresentação. Ele consiste na ideia fundamental de que, do mesmo modo que ninguém vem ao Pai senão pelo Filho (João 14, 6) mas o Filho não é o Pai, isto é, do mesmo modo que Deus Pai se torna presente na pessoa de Cristo mas não se confunde com ela, assim também o Papa torna visível e presente a pessoa de Cristo mas não é o próprio Cristo, não se confunde com ele e é somente o seu representante. Representar, neste sentido, consiste, para Schmitt, em tornar visível e apresentar, através de um ente visível, exposto e presente publicamente, um ente que só adquire existência visível através do próprio processo representativo. No seu livro de 1928 Doutrina da Constituição, Schmitt descreve este processo da seguinte maneira: "Representar quer dizer tornar visível e actualizar um ser invisível através de um ser publicamente presente. A dialéctica do conceito está em que o invisível é pressuposto como ausente e, no entanto, ao mesmo tempo, se torna presente"4.

O segundo princípio, articulado com o primeiro, poderia ser designado como princípio da mediação. Um tal princípio alude à noção de que a representação consiste no modo pelo qual algo que em si é intrinsecamente transcendente, invisível e inacessível, se realiza, tornando-se visível e propriamente real, no mundo imanente do aquém. Por outras palavras, o princípio da mediação permite compreender a representação como um processo pelo qual dois polos heterogéneos se relacionam enquanto heterogéneos: um processo pelo qual são unidos, mantendo-se incomensurável e radicalmente diferenciados, Céu e Terra, Além e Aquém, Transcendente e Imanente. No contexto da Igreja, dir-se-ia que Cristo é o mediador por excelência, reunindo em si em uma única Pessoa, misteriosamente, duas naturezas inteiramente heterogéneas e separadas, uma natureza divina e humana. Do mesmo modo, constituindo-se como o legado de Cristo no mundo depois da sua encarnação e presença visível entre os homens, a Igreja seria a estrutura mediadora pela qual a própria relação entre Deus e o mundo se manteria. Por fim, neste contexto, também o Papa seria um mediador, e seria esta mediação que se traduziria no seu estatuto enquanto Stellvertreter Christi, enquanto vigário, lugar-tenente ou representante de Cristo. Enquanto mediador, o Papa asseguraria a

${ }^{4}$ Carl Schmitt. Verfassungslehre. Berlin: Duncker \& Humblot, 1993, pp. 209-210.

R. Inter. Interdisc. INTERthesis, Florianópolis, v.12, n.1, p.130-146, Jan-Jun. 2015 
relação entre Cristo e o mundo, relacionando o que está separado enquanto separado.

Finalmente, o terceiro princípio subjacente ao estabelecimento da unidade política poderia ser identificado como um princípio de decisão. Se o representado apenas vem a ser visível através do representante e na pessoa do próprio representante, e se o representante é o mediador pelo qual se torna possível aceder à própria realidade por ele representada, é este mesmo representante que pensa, fala e decide em nome do representado, constituindo assim o próprio conteúdo do seu pensamento, os contornos das suas manifestações e as determinações da sua decisão. Na Igreja católica, o dogma da infalibilidade papal adquire neste princípio a sua justificação. $O$ estatuto do Papa enquanto representante de Cristo, e enquanto mediador que relaciona transcendência e imanência, determina-lhe a possibilidade do estabelecimento de uma decisão absoluta e inapelável. Não é enquanto detentor de um poder autocrático que o Papa se pode constituir como representante de Cristo e mediador do divino. Mas é na medida em que representa Cristo, tornando-o presente entre os homens, e na medida em que é o essencial mediador na relação dos homens com Deus, ligando-os e assegurando a sua relação, que o Papa não pode deixar de se caracterizar por um poder de falar excathedra e decretar uma decisão infalível. Se é na pessoa do Papa que o poder de Deus se torna presente e Cristo se torna visível, a decisão papal não é uma decisão limitada, condicionada por um mandato que the determina o conteúdo, mas uma decisão absoluta que decide sem constrangimentos nem limitações.

Passando de um plano teológico para um plano jurídico e político, poder-se-ia dizer que Schmitt transporta esta mesma estrutura triádica subjacente à instituição da unidade política para um novo plano. Assim, aplicando o princípio da representação a um plano político e jurídico, Schmitt alude ao conceito de ordem como algo de transcendente que, enquanto tal, não pode deixar de ser realizado através de um processo representativo. Para Schmitt, a ordem é uma realidade superior, transcendente e que ultrapassa o domínio imanente em que se encontram as leis, as normas e a ordem jurídica. Neste sentido, a primeira abordagem que se pode fazer da sua realidade é negativa: a ordem é, para Schmitt, algo que não é simples lei, que não se pode confundir com a mera norma, algo que se subtrai sempre à ordem jurídica e lhe permanece sempre irredutível. Tal quer dizer, 
portanto, que a ordem é uma realidade transcendente que está presente na ordem jurídica sem com ela se identificar. Tal como Cristo está presente na Igreja sem com ela se confundir, dir-se-ia que a ordem está presente na ordem jurídica de uma sociedade política, mas ultrapassa essa mesma ordem. Para Schmitt, a ordem é anterior às normas e à ordem jurídica, e, tornando-se nela presente enquanto condição de possibilidade da normalidade que esta mesma ordem jurídica pressupõe, requer um representante que possa estar livre para a criar e proteger. Como escreve Schmitt no livro Teologia Política, de 1922: "Não há norma que fosse aplicável a um caos. A ordem tem de ser criada para que a ordem jurídica tenha um sentido. Tem de ser alcançada uma situação normal, e é soberano aquele que decide definitivamente sobre se este estado normal realmente domina"5. No seu livro de juventude de 1914, O Valor do Estado, Schmitt alude a esta transcendência da ordem através de uma expressão curiosa: ele fala aqui de um "direito natural sem naturalismo" 6 . Esta expressão só através da alusão ao princípio da representação se torna inteligível: por um lado, ao falar de um "direito natural", Schmitt evoca justamente a transcendência de um direito caracterizado pela sua irredutibilidade ao plano fáctico e imanente das normas e das leis; por outro, dizendo que este "direito natural" é sem naturalismo, ele alude a que esta transcendência só existe e se realiza ao ser representada por uma decisão que, no plano fáctico e imanente de uma ordem jurídica, fale, decida em seu nome e lhe defina o conteúdo.

A anterioridade da ordem em relação à ordem jurídica, a sua precedência em relação à ordem jurídica como condição de possibilidade desta, alude, então, aos restantes dois princípios subjacente ao estabelecimento da unidade política. Por um lado, a relação entre ordem e ordem jurídica não pode deixar de manifestar aquilo a que se poderia chamar um princípio de mediação. Se a ordem e a ordem jurídica são essencialmente heterogéneas e se situam em planos distintos, se elas têm entre si uma relação análoga à relação entre transcendência e imanência, tal quer dizer que, na sua relação com a realidade, a ordem não pode deixar de requerer uma instância que medeie a sua relação com a realidade fáctica, traduzindo-a numa ordem jurídica. É como esta instância que, no pensamento político de Schmitt, o Estado aparece. Para Schmitt, o "valor do Estado" consiste precisamente em este

\footnotetext{
${ }^{5}$ Carl Schmitt. PolitischeTheologie. Berlin: Duncker\&Humblot, 1996, p. 19.

${ }^{6}$ Cf. Carl Schmitt. Der Wert des Staates.Tübingen: Verlag J. C. B. Mohr, 1914, p. 76
}

R. Inter. Interdisc. INTERthesis, Florianópolis, v.12, n.1, p.130-146, Jan-Jun. 2015 
ser uma realidade que medeia a relação entre transcendência e imanência, uma realidade que, pertencendo ao plano da facticidade, traduz a realização fáctica de uma ideia que, enquanto ideia, pertence a uma outra esfera: aquilo a queSchmitt chama a ideia do direito (ou o "direito" enquanto ideia). Daí que Schmitt possa afirmar, no seu livro de juventude, que "o sentido do Estado consiste na sua tarefa de realizar o direito no mundo"7. Por outro lado, se o Estado é a estrutura mediadora pela qual a ideia do direito se realiza no plano fáctico, se ele é a mediação pela qual a ordem vem a ser facticamente como ordem jurídica, tal quer dizer que a prioridade do Estado enquanto condição de realização do direito no mundo, oua anterioridade da ordem em relação às normas ou à ordem jurídica presentes na realidade fáctica, não pode deixar de evocar um princípio de decisão análogo ao princípio da decisão infalível do Papa. É precisamente a esta decisão que Schmitt chama "soberana". A irredutibilidade da ordem à ordem jurídica abre a possibilidade de que ocorra uma situação excepcional na qual a preservação da ordem (e a defesa do Estado) requeira a suspensão da ordem jurídica de que ela própria é fundamento. $O$ "estado de excepção" caracteriza-se precisamente como a situação paradoxal na qual se evoca a possibilidade de uma decisão suspender a ordem jurídica em nome de uma ordem onde se encontra acondição para que essa mesma ordem jurídica possa vigorar. E a soberania surge, assim, como a possibilidade de decidir o estado de excepção ${ }^{8}$.

Tendo em conta a abordagem por Schmitt do conceito de representação, torna-se possível compreender que esta se encontre ligada à adopção de uma atitude política que poderia ser caracterizada como uma defesa da soberania. Uma tal atitude manifesta-seemtrês posições fundamentais, decorrentes precisamente da sua compreensãodo conceito de representação. Em primeiro lugar, enquanto jurista, Schmitt centra-se numa crítica fundamental de uma posição normativista sobre o direito. Face à tese de que o direito consiste essencialmente numa realidade normativa, e de que a vigência do direito é simplesmente vigência de normas jurídicas, Schmitt sustenta sobre o direito uma tese decisionista: a tese de que o direito é irredutível a uma dimensão normativa e de que, nessa medida, abrange uma decisão que, sendo condição da realização desse mesmo direito, não pode ser

${ }^{7}$ Id., Der Wert des Staates, p. 55.

${ }^{8}$ Daí a definição de soberano que inicia o texto de Teologia Política: "Soberano é quem decide sobre o estado de excepção" (PolitischeTheologie, p. 13).

R. Inter. Interdisc. INTERthesis, Florianópolis, v.12, n.1, p.130-146, Jan-Jun. 2015 
determinada nem limitada pela sua normatividade. Como Schmitt afirma,

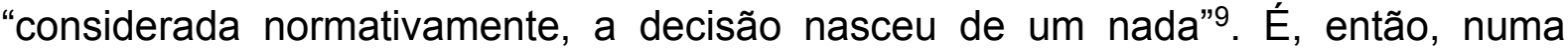
posição jurídica decisionista que se traduz, antes de mais, a ideia de uma irredutibilidade da ordem à norma ou à ordem jurídica. A realização do direito no plano da realidade fáctica (Rechtsverwirklichung) seria uma dimensão não extrínseca, mas intrínseca ao direito (Recht) enquanto tal; e, por essa razão, a decisão pela qual o direito se realizaria facticamente constituiria um momento autónomo do próprio direito, não podendo o direito, consequentemente, ser compreendido como algo pura e simplesmente normativo. Em segundo lugar, enquanto teórico político, Schmitt defende que a alusão decisionista a um momento autónomo da decisão não pode deixar de se traduzir na defesa de que haja, no plano político, um poder soberano enquanto poder que se situe acima das normas, isto é, um poder que possa, em função da situação fáctica, suspender essas mesmas normas e abrir um estado de excepção em relação a elas. Finalmente, em terceiro lugar, enquanto constitucionalista, Schmitt defende uma leitura decisionista da Constituição (no caso da Alemanha das décadas de 20 e 30, uma leitura decisionista da Constituição de Weimar, de 1919): uma leitura pela qual a Constituição fosse considerada não um mero encadeamento de normas, mas uma ordem que, traduzindo-se numa decisão existencial, deveria poder ser defendida por um poder capaz de suspender excepcionalmente, quando necessário, a sua própria estrutura normativa. Noutros termos, enquanto constitucionalista, Schmitt propõe que a Constituição de Weimar seja lida como depositando no Presidente do Reich, através do seu art. $48^{\circ}$, um poder ditatorial de suspender a ordem jurídica em nome da proteç̧ão da forma política do Estado e da preservação de uma ordem que ultrapassao carácter normativo dessa mesma Constituição. Em textos como $A$ Ditadura, de 1921, e Doutrina da Constituição, de 1928, Schmitt elabora precisamente esta proposta.

O pensamento de Schmitt, no desenvolvimento do seu conceito de representação, culmina assim na proposta de que ao Presidente do Reich seja reconhecida a prerrogativa constitucional de poder decidir suspender a própria Constituição, em função da sua condição de representante de uma ordem anterior, superior e irredutível à ordem jurídica. Se a ordem seria irredutível às normas

${ }^{9}$ Id., PolitischeTheologie, pp. 37-38.

R. Inter. Interdisc. INTERthesis, Florianópolis, v.12, n.1, p.130-146, Jan-Jun. 2015 
jurídicas enquanto sua condição de possibilidade, e se essa ordem careceria de poder ser defendida pela possibilidade de uma decisão destituída de limitações normativas, tal quereria dizer que a possibilidade de uma tal decisão por parte do Presidente do Reich, a atribuição ao Presidente daquilo que Schmitt evoca como um "resíduo" de soberania10, seria ela mesma uma condição de possibilidade das próprias normas jurídicas e de uma vigência normal da Constituição. Dir-se-ia como afirmei noutro lugar ${ }^{11}$ - que esta decisão apontaria para uma ordem irredutível à normatividade como a sua ratio cognoscendi, e que o faria precisamente porque só uma ordem com estas características, só a essencial irredutibilidade da ordem à ordem jurídica, se poderia constituir como a ratio essendi dessa mesma decisão. $\mathrm{O}$ pensamento político de Schmitt baseia-se essencialmente na ideia de que o direito, e a ordem política de um modo geral, não podem prescindir da soberania como o alicerce que o garante e sustenta. Ele manifesta-se, assim, como a defesa de um princípio da representação pelo qual seja reconhecida a necessidade, para a constituição de uma unidade política, de um representante dessa mesma unidade: um representante através do qual a ideia dessa unidade seja realizada facticamente no mundo e cujo poder, em virtude da sua função mediadora entre a ideia da unidade política e a realidade concreta em que esta se realiza, possa traduzir-se na possibilidade de uma decisão livre de limitações e constrangimentos normativos.

A defesa por Schmitt de que a Constituição abra a possibilidade de um poder se assumir como soberano, situando-se acima das normas e podendo decidir a sua suspensão num estado de excepção, levada a cabo no contexto político alemão da República de Weimar, não pode deixar de se desenvolver em articulação com a ideia de democracia. Schmitt encontra na democracia moderna, essencialmente, a designação de uma era política marcada pela abolição dos privilégios nobiliárquicos e pela consequente noção de que um povo deve ser soberano. Por outras palavras, para Schmitt, o conceito de democracia está ligado à noção de soberania popular, à ideia de que um povo é uma unidade política capaz de, de algum modo, autodeterminar-se e autogovernar-se, e, portanto, ao princípio segundo o qual entre o povo governado e o poder governante deve haver um princípio de identidade. De acordo com este princípio de identidade, uma Constituição não pode deixar de ser

${ }^{10}$ Carl Schmitt. Die Diktatur. Berlin: Duncker\&Humblot, 1994, p. 239.

${ }_{11}$ Cf. Alexandre Franco de Sá. O PoderpeloPoder. Lisboa: Centro de Filosofia da Universidade de Lisboa, 2009, pp. 663-664.

R. Inter. Interdisc. INTERthesis, Florianópolis, v.12, n.1, p.130-146, Jan-Jun. 2015 
encarada não como um conjunto de normas, mas como uma decisão existencial pela qual um povo se autodetermina na sua forma política. $E$ tal quer dizer que, para Schmitt, pelo menos numa era democrática, o princípio da representação - o princípio pelo qual uma instância soberana surge como um poder situado acima das normas na medida em que é constituinte da unidade política - não pode deixar de ser complementado com um princípio da identidade, o qual exige que a representação nunca deixe de ter subjacente o reconhecimento dos governantes pelos governados, um princípio de identificação pelo qual os governados assumam o seu governo como um governo deles mesmos sobre si mesmos. Numa era democrática, sem esta identidade subjacente à representação, sem uma convergência identitária entre governantes e governados, um governo seria pura e simplesmente uma tirania. Daí que, na sua abordagem da Constituição, Schmitt apresente representação e identidade como os dois princípios que não podem deixar de convergir na determinação de uma forma política: "Na realidade da vida política, há tão pouco um Estado que pudesse renunciar a todos os elementos estruturais do princípio da identidade, como um Estado que pudesse renunciar a todos os elementos estruturais da representação. Também onde for feita a tentativa de realizar incondicionalmente uma identidade absoluta, os elementos e métodos da representação permanecem incontornáveis, como, ao invés, nenhuma representação é possível sem representações de identidade. Estas duas possibilidades, identidade e representação, não se excluem, mas são apenas os dois pontos de orientação contrapostos para a configuração concreta da unidade política"12.

É a abordagem desta convergência entre representação e identidade que nos poderá fazer compreender, em última análise, a confrontação crítica de Schmitt com aquilo a que se poderia chamar uma "democracia representativa". Por um lado, Schmitt insiste na ideia de que compreender o direito como pura realidade normativa, ignorando a possibilidade de ser necessário introduzir um estado de excepção, isto é, procurando ignorar que o Estado é a manifestação de uma ordem superior e irredutível às normas jurídicas, é, no fundo, fragilizar o próprio direito, deixando desprotegida a ordem que é o seu pressuposto. Noutros termos, Schmitt insiste na ideia de que o direito requer a adopção de um princípio de representação

12 Id., Verfassungslehre, pp. 205-206.

R. Inter. Interdisc. INTERthesis, Florianópolis, v.12, n.1, p.130-146, Jan-Jun. 2015 
através do qual seja nele introduzido o reconhecimento de uma decisão enquanto momento autónomo em relação à dimensão normativa. Por outro lado, Schmitt tem consciência de que, numa era democrática, a representação não pode dispensar a sua articulação com um princípio de identidade, com um princípio de autodeterminação que estabeleça o governo como um autogoverno do povo. A identidade entre governantes e governados é, no entanto, para Schmitt aquilo a que se poderia chamar uma "ideia reguladora". Se é verdade que,numa era democrática, ela tem de estar sempre pressuposta como critério fundamental de legitimação de um governo, também o é que entre governantes e governados há sempre uma distância, uma diferença ou uma não coincidência que torna o princípio da identidade, em concreto, a exigência de uma identificação. Dizer que o povo se governa democraticamente a si mesmo, na sua identidade consigo mesmo, significadizer, no fundo, que um governo democrático se legitima ao identificar a sua vontade com a vontade do povo, ocupando-se essencialmente com os meios necessários à formação dessa mesma vontade. A era da democracia é, então, a era em que, assumindo o princípio da identidade como o princípio essencial da legitimidade política, o combate político se desenvolve a partir da disputa em torno dos meios capazes de mobilizar o povo, configurando a sua "visão do mundo" e determinando a sua vontade. Daí que, ao caracterizar a democracia em 1923, Schmitt afirme que "a única questão prática diz respeito à identificação, nomeadamente a questão de quem dispõe dos meios para formar a vontade do povo: poder militar e político, propaganda, domínio sobe a opinião pública através da imprensa, organizações partidárias, reuniões, educação popular, escolar"13: "Em vista da expansão do pensamento democrático, pode-se hoje dizer que aquela identidade com a vontade do povo se tornou de tal forma uma premissa comum que deixou de ser politicamente interessante e o combate se move apenas ainda em torno dos meios de identificação"14. Assim, a era da democracia é, para Schmitt, uma era em que o combate político se torna particularmente invasivo, convertendose numa disputa pela capacidade de politização em todas as esferas da vida social. E é esse o aspecto central da abordagem por Schmitt de uma era democrática: na transição entre as décadas de 20 e 30 do século XX, tratar-se-ia, para Schmitt, de

13 Carl Schmitt. Die geistesgeschichtlicheLage des heutigenParlamentarismus. Berlin: Duncker\&Humblot, 1996, pp. 37-38.

14 lbid., p. 38.

R. Inter. Interdisc. INTERthesis, Florianópolis, v.12, n.1, p.130-146, Jan-Jun. 2015 
tentar pensar o modo como se poderia encontrar um obstáculo a esta politização absoluta que uma era democrática, baseada no princípio da identidade, parecia exigir.

É sobretudo nos anos da crise final da República de Weimar, entre 1931 e a chegada de Hitler ao poder, em Janeiro de 1933, que, segundo Schmitt, o problema fundamental da democracia se teria tornado particularmente manifesto. Sobretudo a partir desse ano, tornara-se patente, na Alemanha, que os partidos radicais no seio do parlamento alemão, o Partido Comunista Alemão (KPD) e o Partido NacionalSocialista dos Trabalhadores Alemães (NSDAP), pretendiam observar as normas constitucionais e usar a legalidade para, a partir dos meios legais ao seu dispor, derrubar a República de Weimare converter a Alemanha num Estado consentâneo com aquilo a que chamavam a sua Weltanschauung, a sua "visão do mundo": no caso dos comunistas, propunha-se transformar a Alemanha numa República operária e soviética; no caso dos nazis, defendia-se a transformação da Alemanha num "Estado do povo", numa comunidade de povo (Volksgemeinschaft) baseada no princípio racista da pureza racial. Em ambos os casos, um Estado cuja ordem não fosse considerada como algo superior à mera vigência da ordem jurídica normal, um Estado cuja defesa se não pudesse impor excepcionalmente por cima das próprias normas, isto é, um Estado cuja legitimidade se reduzisse à pura e simples legalidade, seria um Estado demasiado fraco para fazer face, de forma eficiente, aos desafios que estes movimentos colocavam. Se nazis e comunistas se propunham, na Alemanha de Weimar, mobilizar a população alemã e fanatizá-la, usando a legalidade para reivindicar uma neutralidade do Estado diante da sua liberdade de propaganda e de mobilização, Schmitt procura pensar, nesta mesma época, o modo como o Estado poderia ter força suficiente para se defender, a si e à sua Constituição.

Ao abordar o tema da democracia, o problema central considerado por Schmitt é, então, o do enfraquecimento do Estado diante de movimentos que o procurariam subverter através da propaganda, mobilizando, fanatizando e manipulando o próprio povo. Um Estado fraco, um Estado que não se considerasse como uma ordem ou um "valor" situado acima da sua estrutura normativa, seria um Estado incapaz de se defender num caso excepcional ou numa crise deste tipo. Diante dessa sua incapacidade, os movimentos e partidos usariam a legalidade das 
normas para ocuparem o próprio Estado, preenchendo a sua estrutura, o aparelho de Estado, com os elementos dospartidos, e convertendo este mesmo Estado num mero defensor e numa mera expressão dos seus interesses e da sua "visão do mundo". Um Estado ocupado por interesses partidários, pela sua "visão do mundo" e pelos seus funcionários, seria um Estado que promoveria essa mesma "visão do mundo" e, como tal, interviria em todos os aspectos que diriam respeito a essa visão. Se uma "visão do mundo" consiste numa visão englobante, numa totalidade de sentido, tal quereria dizer que um tal Estado seria um "Estado total" na medida em que interviria em todos os aspectos da vida, politizando, portanto, a totalidade da própria vida. O Estado total, no qual, segundo Schmitt, culminaria o desenvolvimento do Estado na era democrática, seria um Estado que, por fraqueza, seria impotente para enfrentar a sua conquista por uma pluralidade de partidos que, através dele, politizariam toda a vida social e o colocariam ao seu serviço. Segundo Schmitt, "um Estado pluralista de partidos torna-se 'total' não por fortaleza e força, mas por fraqueza; ele intervém em todas as áreas da vida porque tem de satisfazer as reivindicações de todos os interessados"15:"Este tipo de Estado total é um Estado que se imiscui indiferenciadamente em todas as áreas objectivas, em todas as esferas da existência humana, não conhecendo de todo qualquer esfera livre do Estado porque já não pode de todo diferenciar. [...] Tal é naturalmente uma totalidade apenas no sentido do simples volume e o contrário de força e fortaleza. $O$ Estado alemão hodierno é total por fraqueza e ausência de resistência, por incapacidade de fazer face ao assalto dos partidos e dos interesses organizados" 16 .

A confrontação crítica de Schmitt com a "democracia representativa", a qual se desenvolve sobretudo no contexto da instabilidade política da República de Weimar, encontra-se suficientemente circunscrita. Uma tal confrontação crítica pode, então, sintetizar-se em três pontos. Em primeiro lugar, Schmitt desenvolve uma análise da República de Weimar segundo a qual esta, enquanto democracia liberal, com os seus partidos e a sua legalidade constitucional, com o normativismo subjacente à sua compreensão do Estado de direito, teria enfraquecido o Estado a ponto de este ignorar a irredutibilidade da ordem à ordem jurídica, deixando de se poder compreender como um "valor" superior à vigência das normas (um "valor" que,

${ }^{15}$ Carl Schmitt. Legalität und Legitimität. Berlin: Duncker \& Humblot, p. 89.

${ }^{16}$ Carl Schmitt. "Weiterentwicklung des totalen Staates in Deutschland". inPositionen und Begriffe. Berlin: Duncker \& Humblot, 1988, p. 213.

R. Inter. Interdisc. INTERthesis, Florianópolis, v.12, n.1, p.130-146, Jan-Jun. 2015 
como vimos, não poderia deixar de ser representado como um pressuposto, uma condição de possibilidade da vigência dessas mesmas normas). Por outras palavras, Schmitt caracteriza a "democracia representativa" sua contemporânea por uma espécie de fuga romântica à realidade: uma fuga pela qual esta preferiria ignorar a ocorrência de crises e de momentos em que um Estado se precisaria de defender em situações assinaláveis como um estado de excepção.

Em segundo lugar, segundo Schmitt, o enfraquecimento da autoridade do Estado tinha conduzido ao aparecimento de partidos e movimentos que, usando o espaço aberto pela legalidade, procurariam mobilizar a sociedade e, através dessa mobilização, ocupar o Estado e colocá-lo ao serviço dos seus interesses e da sua "visão do mundo". A propaganda, o assédio às consciências e à opinião pública ${ }^{17}$, o desenvolvimento de técnicas crescentemente sofisticadas de determinação e mobilização da esfera pública, seriam essencialmente novos fenómenos cujo perigo o Estado não poderia ignorar. Para Schmitt, a "democracia representativa" oferecia um problema político que ultrapassava o problema tradicional do domínio pelo Estado de um aparelho repressivo, baseado no controlo do exército, da polícia e das forças capazes de exercer o domínio no espaço exterior. O papel dos partidos e dos movimentos na democracia representativa mostraria agora um problema novo: o problema de um Estado fraco e impotente diante do domínio, por parte dos partidos e movimentos presentes na sociedade, de técnicas de mobilização social, de manipulação afectiva e de controlo de consciências, potencialmente invasivas e politizadoras de todas as dimensões da vida.

Por fim, em terceiro lugar, a crítica de Schmitt, diante desta descrição, não pode deixar de se traduzir na tese de que só um reforço da autoridade do Estado, uma afirmação desta autoridade diante dos partidos e dos movimentos presentes na sociedade, se poderia constituir como uma barreira face à sua crescente destruição. Para tal, Schmitt propõe que o Estado não ignore a emergência destes novos poderes, mas assuma a sua existência e se aproprie deles, monopolizando-os e constituindo-se como juiz do seu uso. Diante de uma "democracia representativa", normativista e liberal, que evocaria crescentemente uma neutralidade do Estado diante da sociedade, Schmitt evoca a necessidade de um Estado forte que, para não

${ }^{17}$ Schmitt dedica atenção aos estudos de Edward Bernays e de Walter Lippmann, pioneiros no estudo da manipulação da opinião pública e da propaganda.

R. Inter. Interdisc. INTERthesis, Florianópolis, v.12, n.1, p.130-146, Jan-Jun. 2015 
intervir permanentemente em todos os âmbitos da vida social, assuma e monopolize o direito de abrir excepções às normas e de intervir excepcionalmente onde essa intervenção seja considerada necessária. Para Schmitt, a liberdade só poderia ser assegurada, evitando a mobilização, manipulação e politização total da sociedade, se o Estado se constituísse como um "valor" cuja legitimidade se situasse acima da legalidade, um "valor" que se sobrepusesse, caso fosse necessário, às próprias normas e leis que partidos e movimentos radicais procurariam utilizar para $o$ subverter por dentro. 


\title{
REPRESENTATIVE DEMOCRACY: CARL SCHMITT'S CRITICS
}

\begin{abstract}
:
The present text tries to show, on the one hand, the basis of Schmitt's concept of representation. It shows how this concept is essentially linked with the concepts of mediation and decision. From this point, the article shows, on the other hand, how the concept of representation allows him to develop a political thought that is able to critically understand contemporary democratic societies' fundamental problems.
\end{abstract}

Keywords: Representation. Mediation. Decision. Democracy.

\section{DEMOCRACIA REPRESENTATIVA: LAS CRÍTICAS DE CARL SCHMITT}

\section{Resumen:}

Este trabajo tiene como objetivo, por un lado, mostrar la base del concepto de Schmitt de la representación. Él muestra cómo con este concepto se conecta esencialmente los conceptos de mediación y decisión. A partir de ahí, el artículo muestra, por otra parte, como el concepto de representación le permite desarrollar un pensamiento político que puede comprender críticamente los problemas fundamentales de las sociedades democráticas contemporáneas.

Palabras clave: Representación. Mediación. Decisión. Democracia.

\section{Artigo:}

Submetido em 10.06.2015

Aceito em 26.06.2015 